\title{
Review Article: A Critique
}

\author{
Abhinav Dixit \\ Received: 24 October 2009 / Accepted: 5 March 2012 /Published online: 17 March 2012 \\ (C) Association of Surgeons of India 2012
}

\section{Dear Editor,}

I read the review article 'Principles of Physics in Surgery: The Laws of Flow Dynamics Physics for Surgeons-Part I' by Srivastava et al. [1] in July-August 2009 issue, pages 182187 with great interest. The authors have very well summarized the various laws of physics applicable to haemodynamics.

I am a regular reader of the Indian Journal of Surgery, but the publication of this 'Review Article' raises certain issues, which I believe should be considered by the editorial board.

The title of the article gives an impression as if the laws of physics cited are applicable only to surgery. On the contrary, the authors could have used the word 'Medical Science' rather than surgery, because these laws are applicable to haemodynamics with which all clinical specialties have to deal with and not only surgeons.

The article is nothing but a summary of well-established facts and chapters published in various text books of physics and physiology. A look at the reference list clearly brings this to light: Of the 17 references, 11 are textbooks and 6 of these are from only two textbooks [2,3]. I wish to bring forth the fact, that the laws and their applications summarized are taught to undergraduate (MBBS) medical students during their first year of graduation, and hence it is difficult to believe that surgeons are unaware of these basic principles and a review article is required.

A review article should not be just a mere presentation of facts that are well documented. It's hard to believe that a journal like Indian Journal of Surgery has published nothing more than textbook knowledge as a review article.

This letter should be viewed as a healthy comment for the growth and betterment of Indian medical journals in general.

\section{References}

1. Srivastava A, Sood A, Joy SP, Woodcock J (2009) Principles of physics in surgery: the laws of flow dynamics physics for surgeons - part I. Indian J Surg 71:182-187

2. Guyton A, Hall J (2003) Textbook of medical physiology, 10th ed. Elsevier

3. Halliday D, Resnick R, Walker J (2001) Fundamentals of physics, 6th edn. Wiley, Singapore

\footnotetext{
A. Dixit $(\square)$

Department of Physiology,

University College of Medical Sciences (Delhi University),

Dilshad Garden,

Delhi 110095, India

e-mail: abhinavdr@yahoo.com 